\title{
Cross-sectional Associations of Fatigue with Cerebral $\beta$-Amyloid in Older Adults at Risk of Dementia
}

\author{
Claudie Hooper ${ }^{1 *}$, Philipe De Souto Barreto ${ }^{1,2}$, Nicola Coley ${ }^{2,3}$, Matteo Cesari 1,2, \\ Pierre Payoux ${ }^{4,5}$, Anne Sophie Salabert ${ }^{4,5}$, Sandrine Andrieu ${ }^{1,2,3}$ and Bruno Vellas ${ }^{1,2}$ \\ for the MAPTIDSA Study Group
}

'Gérontopôle, Department of Geriatrics, CHU Toulouse, Purpan University Hospital, Toulouse, France, ${ }^{2}$ UMR1027 INSERM, Université de Toulouse III Paul Sabatier, Toulouse, France, ${ }^{3}$ Department of Epidemiology and Public Health, CHU Toulouse, Toulouse, France, ${ }^{4}$ UMR 1214, Toulouse Neuroimaging Center, University of Toulouse III, Toulouse, France, ${ }^{5}$ Department of Nuclear Medicine, CHU Toulouse, Toulouse, France

OPEN ACCESS

Edited by: Wee Shiong Lim, Tan Tock Seng Hospital, Singapore

Reviewed by:

Mario Ulises Pérez-Zepeda, Instituto Nacional de Geriatría,

Mexico

Liang-Yu Chen,

Taipei Veterans General Hospital,

Taiwan

*Correspondence:

Claudie Hooper claudie28@yahoo.com

Specialty section:

This article was submitted

to Geriatric Medicine,

a section of the journal

Frontiers in Medicine

Received: 24 August 2017 Accepted: 29 September 2017 Published: 06 November 2017

Citation:

Hooper C, De Souto Barreto $P$,

Coley N, Cesari M, Payoux P, Salabert AS, Andrieu $S$ and Vellas $B$ (2017) Cross-sectional Associations of Fatigue with Cerebral $\beta$-Amyloid in Older Adults at Risk of Dementia. Front. Med. 4:173. doi: 10.3389/fmed.2017.00173
Fatigue is a common symptom in the elderly and has also been associated with impaired cognition in older adults. Hence, we sought to explore the cross-sectional relationship between fatigue and cerebral $\beta$-amyloid (A $\beta$ ) in 269 elderly individuals reporting subjective memory complaints from the Multidomain Alzheimer Preventive Trial. Standard uptake value ratios (SUVRs) were generated by $\left[{ }^{18} \mathrm{~F}\right]$ florbetapir positron emission tomography (PET) using the cerebellum as a reference. Cortical-to-cerebellar SUVRs (cortical-SUVRs) were obtained using the mean signal from the frontal cortex, temporal cortex, parietal cortex, precuneus, anterior cingulate, and posterior cingulate. Other brain regions independently assessed were the anterior cingulate, anterior putamen, caudate, hippocampus, medial orbitofrontal cortex, occipital cortex, parietal cortex, pons, posterior cingulate, posterior putamen, precuneus, semioval center, and temporal cortex. Fatigue was defined according to two questions retrieved from the Center for Epidemiological Studies-Depression scale. Chronic fatigue was defined as meeting fatigue criteria at two consecutive clinical visits 6 months apart between study baseline and 1 year (visits were performed at baseline, 6 months and 1 year then annually). Cross-sectional associations between fatigue variables and cerebral $A \beta$ were explored using fully adjusted multiple linear regression models. We found no statistically significant cross-sectional associations between fatigue assessed at the clinical visit closest to PET and $A \beta$ in any brain region. Similarly, chronic fatigue was not significantly associated with $A \beta$ load. Sensitivity analysis in subjects with a Clinical Dementia Rating of 0.5 showed that fatigue reported at the clinical visit closest to PET was, however, weakly associated with increased $A \beta$ in the hippocampus (B-coefficient: 0.07, 95\% Cl: 0.01, 0.12, $p=0.016)$. These preliminary results suggest that fatigue might be associated with $A \beta$ in brain regions associated with Alzheimer's disease in subjects in the early stages of disease.

Keywords: fatigue, $\beta$-amyloid, Alzheimer's disease, frailty, cognition

\section{INTRODUCTION}

Fatigue is the sense of persistent general tiredness and exerts a significant negative impact on health status (1). It is a common symptom in older adults and has been suggested to serve as a clinically relevant biomarker for pathological aging (2). Fatigue is specifically associated with physical frailty $(2,3)$ and cognitive frailty, where physical frailty presents with cognitive impairments $(4,5)$. 
Research into fatigue and Alzheimer's disease (AD), the most common form of dementia in the elderly (6), is limited. However, fatigue has been cross-sectionally associated with brain atrophy and compromised cognition in cognitively normal older adults (7) and longitudinally with increased risk of cognitive decline in older adults without dementia (8). Fatigue has also been more frequently reported in patients with dementia at 3-year follow-up (9) and fatigue is a symptom of depression, a condition that often co-presents with dementia $(10,11)$.

In accordance with the amyloid cascade hypothesis of $\mathrm{AD}$, $\beta$-amyloid $(A \beta)$ is thought to be the main driver of $A D$ pathology culminating in neurofibrillary tangle formation, which in turn precipitates neuronal loss and cognitive impairments (12, 13). It has been suggested that fatigue might occur as a result of depleted physiological reserves (14), and fatigue has been associated with increased oxidative stress (15). Moreover, frailty is associated with pro-inflammatory changes (16-18), but due to the biological complexity of the frailty phenotype specific associations with its fatigue component are difficult to distinguish. It seems plausible, therefore, that fatigue might lead to alterations in homeostasis leading to secondary increases in $\mathrm{A} \beta$ deposition especially considering that oxidative stress and inflammation fuel amyloidogenesis (19, 20). Furthermore, polypharmacy and conditions prevalent in the elderly such as anemia and sleep apnea are associated with fatigue (21-25). Sleep apnea has been associated with increased cerebral A $\beta$ (26) and iron deficiency leads to alterations in the expression of genes involved in amyloidogenesis (27). Moreover, polypharmacy is a risk factor for cognitive impairment (28), which potentially might manifest through $\mathrm{A} \beta$-dependent mechanisms. Hence, in this study, we sought to explore the cross-sectional associations between fatigue and cerebral $A \beta$ in older adults reporting subjective memory complaints. We hypothesized that fatigue would be associated with increased cerebral A $\beta$ load.

\section{MATERIALS AND METHODS}

\section{The Multidomain Alzheimer Preventive Trial (MAPT): Standard Protocol Approvals, Registrations, and Ethics}

Data were obtained from a $\left[{ }^{18} \mathrm{~F}\right]$ florbetapir positron emission tomography (PET) study carried out as part of the Multidomain Alzheimer Preventive Trial (MAPT), which was a large phase III, multicentre, randomized, placebo-controlled trial (29) (registration: NCT00672685). The trial had a four-arm design comprising a placebo group and three treatment groups; omega 3 polyunsaturated fatty acid (n-3 PUFA) supplementation, multidomain intervention (involving nutritional and exercise counseling and cognitive training), and n-3 PUFA supplementation plus multidomain intervention. The trial was designed to assess the efficacy of the interventions in slowing cognitive decline in older adults at risk of dementia $(n=1,680)(29)$. In the main analysis of MAPT, no significant effects of any of the interventions were found on the composite cognitive score compared to placebo after adjustment for multiple testing (30). Both the MAPT and $\left[{ }^{18} \mathrm{~F}\right]$ florbetapir PET study were approved by the ethics committee in
Toulouse (CPP SOOM II) and written consent was obtained from all participants.

\section{Participants}

A total of 271 subjects participated in the MAPT- $\left[{ }^{18} \mathrm{~F}\right]$ florbetapir ancillary study. At inclusion, participants were communitydwelling, men and women without dementia, aged $\geq 70$, and who met at least one of the following criteria: spontaneous memory complaints, limitation in executing $\geq 1$ Instrumental Activity of Daily Living or slow gait speed ( $<0.8$ meters $/ \mathrm{sec}$ ). Two participants were excluded because they developed dementia at the clinical assessment closest to PET [Clinical Dementia Rating $(C D R) \geq 1$ ]. Thus, a total of 269 subjects were included in the analyses described here. The participants of the main MAPT study not assessed for cerebral A $\beta$ load were similar to the participants in the PET sub-study in terms of age at baseline (main MAPT study: $75.9 \pm 4.5$ years, PET sub-study: $75.2 \pm 4.2$ years), sex (main MAPT study: 65.6\% female, PET sub-study: $60.2 \%$ female) and cognition at baseline measured as mini mental state examination test score (main MAPT study: $28.0 \pm 1.6$, PET substudy: $28.3 \pm 1.5)$.

\section{$\left[{ }^{18} \mathrm{~F}\right]$ Florbetapir PET}

PET-scans were performed once during MAPT in volunteers using $\left[{ }^{18} \mathrm{~F}\right]$ florbetapir as previously described $(29,31)$. All data acquisitions were begun $50 \mathrm{~min}$ after injection of a mean of $4 \mathrm{MBq} / \mathrm{kg}$ weight of $\left[{ }^{18} \mathrm{~F}\right]$-Florbetapir. Radiochemical purity of $\left[{ }^{18} \mathrm{~F}\right]$-Florbetapir was always superior to $99.5 \%$. Standard uptake value ratios (SUVRs) were generated from semi-automated quantitative analysis using the cerebellum as a reference. Cortical-to-cerebellar SUVRs (cortical-SUVRs) were obtained using the mean signal from the following cortical regions: frontal, temporal, parietal, precuneus, anterior cingulate, and posterior cingulate as previously described (32). Other brain regions independently assessed were the: anterior cingulate, anterior putamen, caudate, hippocampus, medial orbitofrontal cortex, occipital cortex, parietal cortex, pons, posterior cingulate, posterior putamen, precuneus, semioval center, and temporal cortex. A quality control based on semi-quantification process was also performed. The median and interquartile range (IQR) for the time interval between baseline and PET-scan assessment was 487.5 days (IQR: $349-728$ ) and 3.7\% (10 out of 269) of subjects received a PET-scan at study baseline.

\section{Fatigue}

Fatigue was defined according to the following two questions retrieved from the Center for Epidemiological Studies-Depression scale: (a) I felt that everything I did was an effort, (b) I could not get going. The question is asked "How often in the last week did you feel this way?" and subjects score their responses: $0=$ rarely or none of the time ( $<1$ day), $1=$ some or a little of the time (1-2 days), $2=$ a moderate amount of the time (3-4 days), $3=$ most of the time. Subjects answering 2 or 3 to either of these questions were designated as fatigued otherwise subjects were classed as non-fatigued. Subjects were classed as having chronic fatigue if answering 2 or 3 to either of the questions at two consecutive visits between study baseline and 1 year (visits were performed at 
baseline, 6 months, and 1 year after which they were performed annually) otherwise subjects were deemed non-chronically fatigued. The adopted definition of fatigue is commonly used to define the "exhaustion" criterion in the field of frailty (3).

\section{Confounding Variables}

On the basis of data availability and the literature on dementia (33), we selected the following confounders: age at PET-scan assessment, gender, educational level, cognitive status assessed at the clinical visit closest to PET-scan (CDR: scores 0 or 0.5 ), MAPT group allocation (four groups: placebo, multidomain intervention, n-3 PUFA supplementation and multidomain intervention $+n-3$ PUFA supplementation), depressive symptoms assessed closed to PET-scan (Geriatric Depression Scale: scores 0-30) and Apolipoprotein E $\varepsilon 4$ (ApoE ع4) genotype (carriers of at least one $\varepsilon 4$ allele versus non-carriers).

\section{Statistical Analysis}

Descriptive statistics are presented as median (IQR) or absolute values/percentages as appropriate. After completing analysis of the primary hypotheses in MAPT (30), we performed post hoc analyses using multiple linear regression models to explore the cross-sectional relationships between fatigue and cerebral A $\beta$ load (measured as SUVR). Clinical and demographic characteristics were compared between the participants deemed as non-fatigued or fatigued (with fatigue assessed at the clinical exam closest to PET-scan) using chi squared tests for categorical variables and Wilcoxon rank sum tests for continuous variables. We ran multiple linear regression analysis to explore the cross-sectional relationship between fatigue at the clinical exam closest to PET-scan and cortical-SUVR and region specific SUVR (13 regions described above) adjusting for all confounders. Sensitivity analysis was performed in subjects with a CDR score of 0.5 as this sub-group represents those more likely to develop $\mathrm{AD}$ (34). We also ran multiple linear regression analysis to explore the cross-sectional relationship between chronic fatigue and cortical-SUVR and regional SUVR (13 regions) adjusting for all confounders. There was no correction for multiple comparisons due to the exploratory nature of this study: $p<0.05$ was considered statistically significant. All analyses were performed using Stata version 14 (Stata Corp., College Station, TX, USA).

\section{RESULTS}

\section{Sample Characteristics}

Clinical and demographic characteristics of the study participants are shown in Table 1. The median age of the participants was approximately 75 years and around $60 \%$ of the subjects were female and approximately half of the subjects had a CDR score of 0.5. Participants exhibited a high educational level and approximately $30 \%$ of the subjects were ApoE $\varepsilon 4$ carriers. There were no statistically significant differences between subjects classed as non-fatigued or fatigued (with fatigue assessed at the clinical exam closest to PET-scan). A total of 42 participants out of 269 (15.6\%) were classified as fatigued and of these $42.9 \%$ ( 18 out of 42 ) were $\mathrm{A} \beta$ positive using a threshold of mean cortical-SUVR $\geq 1.17$
TABLE 1 | Participant characteristics.

\begin{tabular}{|c|c|c|c|}
\hline Variables & $\begin{array}{c}\text { Non-fatigued } \\
\text { subjects } \\
(n=227)\end{array}$ & $\begin{array}{l}\text { Fatigued } \\
\text { subjects } \\
(n=42)\end{array}$ & $p$-Value \\
\hline Age, years & $75(72-79)$ & $76(73-79)$ & 0.434 \\
\hline Sex, women (\%) & $134(59.0 \%)$ & $28(66.7 \%)$ & 0.353 \\
\hline Education (\%) & & & 0.190 \\
\hline $\begin{array}{l}\text { No diploma or primary school } \\
\text { certificate }\end{array}$ & $54(24.1 \%)$ & $14(34.1 \%)$ & \\
\hline $\begin{array}{l}\text { Secondary education no high- } \\
\text { school diploma }\end{array}$ & $72(32.1 \%)$ & $7(17.1 \%)$ & \\
\hline High-school diploma & $31(13.8 \%)$ & $8(19.5 \%)$ & \\
\hline Higher diploma & 67 (29.9\%) & $12(29.3 \%)$ & \\
\hline Group allocation (\%) & & & 0.550 \\
\hline Multidomain intervention & $57(28.6 \%)$ & $11(26.2 \%)$ & \\
\hline n-3 PUFA supplementation & $48(21.1 \%)$ & $12(28.6 \%)$ & \\
\hline $\begin{array}{l}\text { Multidomain intervention and } n-3 \\
\text { PUFA supplementation }\end{array}$ & $65(28.6 \%)$ & 8 (19.0\%) & \\
\hline Placebo & $57(25.1 \%)$ & $11(26.2 \%)$ & \\
\hline$\%$ of CDR $0.5(\%)$ & $108(47.6 \%)$ & $23(54.7 \%)$ & 0.392 \\
\hline ApoE $\varepsilon 4$ carriers $(\%)^{a}$ & 53 (26.8\%) & 12 (32.4\%) & 0.480 \\
\hline Cortical-SUVR & $1.1(1.0-1.3)$ & $1.1(1.1-1.3)$ & 0.927 \\
\hline
\end{tabular}

Age and CDR score closest to PET-scan are presented. Data are expressed as median (interquartile range) or as absolute values/percentages. Clinical and demographic characteristics were compared between the participants deemed as non-fatigued or fatigued (with fatigue assessed at the clinical exam closest to PET-scan) using chi squared tests for categorical variables and Wilcoxon rank sum tests for continuous variables.

ApoE, apolipoprotein E; CDR, clinical dementia rating; n-3 PUFA, omega 3 polyunsaturated fatty acid; SUVR, standard uptake ratio values.

${ }^{a}$ ApoE $\varepsilon 4$ status available for $n=235$.

$(31,35)$. A total of 26 participants out of 269 (9.7\%) were classified as having chronic fatigue and of these $38.5 \%$ (10 out of 26 ) were A $\beta$ positive.

\section{Exploration of the Relationship between Fatigue and Cerebral A $\beta$}

There were no statistically significant cross-sectional associations of fatigue at the clinical exam closest to PET-scan with cortical or region specific A $\beta$ load after adjustment for all confounders (Table 2). Sensitivity analysis performed in subjects with a CDR score of 0.5 , however, showed a weak positive association between fatigue reported at the clinical exam closest to PET-scan and A $\beta$ load in the hippocampus (Table 3). Chronic fatigue was not significantly associated with cortical $A \beta$ or $A \beta$ found in any other brain region after adjustment for all confounders (Table 4).

\section{DISCUSSION}

In this study, we did not find any significant cross-sectional associations between fatigue (assessed closest to PET-scan examination or chronic) and cortical or region specific $A \beta$ load in our total study population. However, sensitivity analysis in subjects with a CDR of 0.5 showed that fatigue reported closest to PET-scan was associated with increased $A \beta$ load specifically in the hippocampus.

Why fatigue might be specifically associated with hippocampal $\mathrm{A} \beta$ pathology in subjects at increased risk of $\mathrm{AD}(\mathrm{CDR}=0.5)$ requires further research attention. However, there is evidence that fatigue, modeled in rats through the induction of sleep 
TABLE 2 | Multiple linear regressions examining the cross-sectional associations between fatigue at the clinical exam closest to PET-scan and cerebral $\beta$-amyloid load.

\begin{tabular}{|c|c|c|c|c|c|c|}
\hline \multirow[t]{2}{*}{$\beta$-amyloid load } & \multicolumn{3}{|c|}{ Unadjusted model $(n=269)$} & \multicolumn{3}{|c|}{ Adjusted model $(n=231)$} \\
\hline & B-coeff. & $95 \% \mathrm{Cl}$ & $p$-Value & B-coeff. & $95 \% \mathrm{Cl}$ & $p$-Value \\
\hline Cortical-SUVR & -0.01 & $-0.06,0.05$ & 0.800 & -0.04 & $-0.10,0.02$ & 0.184 \\
\hline \multicolumn{7}{|l|}{ SUVR by brain region; } \\
\hline Anterior cingulate & -0.01 & $-0.08,0.06$ & 0.832 & -0.06 & $-0.14,0.02$ & 0.140 \\
\hline Anterior putamen & -0.02 & $-0.12,0.08$ & 0.683 & -0.05 & $-0.17,0.06$ & 0.367 \\
\hline Caudate & 0.05 & $-0.06,0.16$ & 0.344 & 0.04 & $-0.09,0.17$ & 0.532 \\
\hline Hippocampus & 0.02 & $-0.02,0.06$ & 0.263 & 0.04 & $-0.00,0.08$ & 0.071 \\
\hline Medial orbitofrontal cortex & -0.00 & $-0.05,0.04$ & 0.939 & -0.02 & $-0.07,0.03$ & 0.494 \\
\hline Occipital cortex & -0.02 & $-0.08,0.04$ & 0.553 & -0.06 & $-0.13,0.01$ & 0.073 \\
\hline Parietal cortex & -0.03 & $-0.09,0.03$ & 0.339 & -0.06 & $-0.13,0.01$ & 0.080 \\
\hline Pons & -0.01 & $-0.05,0.04$ & 0.702 & -0.00 & $-0.06,0.05$ & 0.896 \\
\hline Posterior cingulate & 0.00 & $-0.06,0.06$ & 0.975 & -0.03 & $-0.10,0.04$ & 0.362 \\
\hline Posterior putamen & -0.01 & $-0.09,0.07$ & 0.727 & -0.02 & $-0.11,0.07$ & 0.667 \\
\hline Precuneus & -0.00 & $-0.08,0.08$ & 0.964 & -0.05 & $-0.13,0.03$ & 0.245 \\
\hline Semioval center & 0.02 & $-0.03,0.08$ & 0.424 & 0.02 & $-0.04,0.09$ & 0.507 \\
\hline Temporal cortex & -0.00 & $-0.06,0.05$ & 0.891 & -0.03 & $-0.09,0.02$ & 0.253 \\
\hline
\end{tabular}

The adjusted model contained fewer subjects due to missing data on confounders.

B-coeff, B-coefficient; Cl, confidence intervals; p, probability; SUVR, standard uptake ratio values.

TABLE 3 | Multiple linear regressions examining the cross-sectional associations between fatigue at the clinical exam closest to PET-scan and cerebral $\beta$-amyloid load in subjects with a CDR score of 0.5 .

\begin{tabular}{|c|c|c|c|c|c|c|}
\hline \multirow[t]{2}{*}{$\beta$-amyloid load } & \multicolumn{3}{|c|}{ Unadjusted model $(n=131)$} & \multicolumn{3}{|c|}{ Adjusted model $(n=113)$} \\
\hline & B-coeff. & $95 \% \mathrm{Cl}$ & $p$-Value & B-coeff. & $95 \% \mathrm{Cl}$ & $p$-Value \\
\hline Cortical-SUVR & -0.01 & $-0.09,0.07$ & 0.829 & -0.03 & $-0.12,0.05$ & 0.438 \\
\hline \multicolumn{7}{|l|}{ SUVR by brain region; } \\
\hline Anterior cingulate & 0.01 & $-0.10,0.11$ & 0.922 & -0.03 & $-0.15,0.09$ & 0.597 \\
\hline Anterior putamen & -0.01 & $-0.15,0.13$ & 0.869 & -0.05 & $-0.21,0.12$ & 0.585 \\
\hline Caudate & 0.08 & $-0.07,0.24$ & 0.276 & 0.11 & $-0.06,0.29$ & 0.204 \\
\hline Hippocampus & 0.04 & $-0.01,0.09$ & 0.106 & 0.07 & $0.01,0.12$ & 0.016 \\
\hline Medial orbitofrontal cortex & 0.00 & $-0.06,0.06$ & 0.974 & 0.00 & $-0.06,0.06$ & 0.973 \\
\hline Occipital cortex & -0.01 & $-0.10,0.08$ & 0.750 & -0.05 & $-0.15,0.04$ & 0.265 \\
\hline Parietal cortex & -0.05 & $-0.14,0.03$ & 0.241 & -0.08 & $-0.16,0.01$ & 0.085 \\
\hline Pons & 0.01 & $-0.06,0.07$ & 0.802 & 0.01 & $-0.06,0.08$ & 0.762 \\
\hline Posterior cingulate & -0.01 & $-0.09,0.08$ & 0.824 & -0.04 & $-0.13,0.05$ & 0.426 \\
\hline Posterior putamen & -0.01 & $-0.11,0.09$ & 0.810 & -0.02 & $-0.14,0.09$ & 0.693 \\
\hline Precuneus & -0.00 & $-0.12,0.11$ & 0.958 & -0.04 & $-0.17,0.08$ & 0.496 \\
\hline Semioval center & 0.04 & $-0.03,0.12$ & 0.249 & 0.06 & $-0.02,0.15$ & 0.147 \\
\hline Temporal cortex & 0.00 & $-0.07,0.08$ & 0.904 & -0.02 & $-0.10,0.06$ & 0.688 \\
\hline
\end{tabular}

The adjusted model contained fewer subjects due to missing data on confounders.

$B$-coeff, B-coefficient; Cl, confidence intervals; $p$, probability; SUVR, standard uptake ratio values.

deprivation, reduces hippocampal as well as cortical dendritic spines (36) and inhibits long-term potentiation and hippocampal dependent learning tasks (37). Thus, it might be that fatigue also modulates cell signaling cascades to promote amyloidogenesis specifically in the hippocampus. In line with this, in mouse models of $\mathrm{AD}$, acute sleep deprivation is associated with increased levels of interstitial brain levels of $A \beta$, whereas chronic sleep deprivation has been associated with increased $A \beta$ plaques (38). Increased brain $A \beta$ load has also been cross-sectionally associated with poor sleep (39) and longer sleep latency (time taken to fall asleep) (40) in human subjects. Oxidative stress is associated with fatigue (15) and pro-inflammatory mediators such as interleukin 6 and C-reactive protein have been associated with frailty (which includes fatigue in the phenotype) $(16,18)$; therefore such signalling intermediates might promote fatigue-induced amyloidogenesis at the molecular level $(19,20)$. Interestingly, fatigue has also been associated with compromised cognition in older adults without dementia $(7,8)$. With this in mind, fatigue might modulate cognition via $\mathrm{A} \beta$-dependent mechanisms in human subjects with early AD. More research is needed to verify the links between fatigue and $A \beta$ deposition, particularly to rule out the possibility that increased $A \beta$ in the brain might precipitate fatigue. A better understanding of the biological basis of fatigue would facilitate such studies.

The strengths of the current study are the large sample size with PET $\left[{ }^{18} \mathrm{~F}\right]$ florbetapir imaging data and the simultaneous 
TABLE 4 | Multiple linear regressions examining the cross-sectional associations between chronic fatigue and cerebral $\beta$-amyloid load.

\begin{tabular}{|c|c|c|c|c|c|c|}
\hline \multirow[t]{2}{*}{$\beta$-amyloid load } & \multicolumn{3}{|c|}{ Unadjusted model $(n=269)$} & \multicolumn{3}{|c|}{ Adjusted model $(n=231)$} \\
\hline & B-coeff. & $95 \% \mathrm{Cl}$ & $p$-Value & B-coeff. & $95 \% \mathrm{Cl}$ & $p$-Value \\
\hline Cortical-SUVR & -0.01 & $-0.08,0.06$ & 0.854 & -0.03 & $-0.10,0.05$ & 0.452 \\
\hline \multicolumn{7}{|l|}{ SUVR by brain region; } \\
\hline Anterior cingulate & -0.01 & $-0.10,0.07$ & 0.760 & -0.05 & $-0.14,0.04$ & 0.293 \\
\hline Anterior putamen & 0.02 & $-0.10,0.15$ & 0.736 & 0.01 & $-0.13,0.14$ & 0.922 \\
\hline Caudate & 0.02 & $-0.11,0.16$ & 0.714 & 0.02 & $-0.13,0.17$ & 0.798 \\
\hline Hippocampus & -0.01 & $-0.06,0.03$ & 0.518 & -0.01 & $-0.06,0.04$ & 0.677 \\
\hline Medial orbitofrontal cortex & -0.01 & $-0.07,0.04$ & 0.687 & -0.02 & $-0.08,0.04$ & 0.433 \\
\hline Occipital cortex & -0.01 & $-0.09,0.06$ & 0.756 & -0.04 & $-0.12,0.04$ & 0.286 \\
\hline Parietal cortex & 0.00 & $-0.07,0.08$ & 0.994 & -0.00 & $-0.08,0.07$ & 0.903 \\
\hline Pons & -0.02 & $-0.08,0.03$ & 0.425 & -0.02 & $-0.08,0.04$ & 0.464 \\
\hline Posterior cingulate & -0.01 & $-0.09,0.06$ & 0.716 & -0.04 & $-0.12,0.04$ & 0.384 \\
\hline Posterior putamen & -0.00 & $-0.10,0.10$ & 0.967 & 0.01 & $-0.10,0.12$ & 0.920 \\
\hline Precuneus & 0.01 & $-0.09,0.10$ & 0.857 & -0.02 & $-0.12,0.08$ & 0.639 \\
\hline Semioval center & -0.00 & $-0.07,0.07$ & 0.943 & -0.01 & $-0.09,0.07$ & 0.847 \\
\hline Temporal cortex & -0.01 & $-0.07,0.06$ & 0.773 & -0.03 & $-0.10,0.04$ & 0.379 \\
\hline
\end{tabular}

The adjusted model contained fewer subjects due to missing data on confounders.

B-coeff, B-coefficient; Cl, confidence intervals; p, probability; SUVR, standard uptake ratio values.

availability of successive fatigue measurements over time enabling the creation of a chronic fatigue variable. Nevertheless, there are some limitations. The main limitation of this study is that it is a secondary analysis of the MAPT imaging sub-study; thus, the study was not specifically powered to address our hypothesis on the association of fatigue with increased cerebral $\mathrm{A} \beta$ load. The cross-sectional nature (due to lack of longitudinal imaging data) precluded the examination of the relationship between fatigue and $A \beta$ temporally. Furthermore, it should be noted that PET-scans were performed throughout the three year period of MAPT, so the study was not of a true cross-sectional nature. Moreover, although used by others $(2,41)$ as a measure of fatigue, the self-reported fatigue variable used here was derived from a questionnaire designed to measure depression and as such may not robustly capture the physiological component of fatigue but rather focus on the psychological element. There was also no data available on other diseases that might contribute to fatigue such as anemia, sleep apnea, or cancer.

In conclusion, we have shown here that fatigue might be associated with increased $A \beta$ in the hippocampus specifically in subjects with an augmented risk of $\mathrm{AD}$. Further research is required to confirm our preliminary findings. A longitudinal study examining the temporal association between fatigue and $\mathrm{A} \beta$ would provide more evidence as to whether fatigue might modulate cerebral $\mathrm{A} \beta$ levels.

\section{MAPT/DSA GROUP REFERS TO}

\section{MAPT Study Group \\ Principal Investigator}

Bruno Vellas (Toulouse); Coordination: Sophie Guyonnet; Project leader: Isabelle Carrié; CRA: Lauréane Brigitte; Investigators: Catherine Faisant, Françoise Lala, Julien Delrieu, Hélène Villars; Psychologists: Emeline Combrouze, Carole Badufle, Audrey Zueras; Methodology, statistical analysis and data management:
Sandrine Andrieu, Christelle Cantet, Christophe Morin; Multidomain group: Gabor Abellan Van Kan, Charlotte Dupuy, Yves Rolland (physical and nutritional components), Céline Caillaud, Pierre-Jean Ousset (cognitive component), Françoise Lala (preventive consultation), Bertrand Fougère (Toulouse). The cognitive component was designed in collaboration with Sherry Willis from the University of Seattle, and Sylvie Belleville, Brigitte Gilbert and Francine Fontaine from the University of Montreal.

\section{Coinvestigators in Associated Centers}

Jean-François Dartigues, Isabelle Marcet, Fleur Delva, Alexandra Foubert, Sandrine Cerda (Bordeaux); MarieNoëlle-Cuffi, Corinne Costes (Castres); Olivier Rouaud, Patrick Manckoundia, Valérie Quipourt, Sophie Marilier, Evelyne Franon (Dijon); Lawrence Bories, Marie-Laure Pader, Marie-France Basset, Bruno Lapoujade, Valérie Faure, Michael Li Yung Tong, Christine Malick-Loiseau, Evelyne Cazaban-Campistron (Foix); Françoise Desclaux, Colette Blatge (Lavaur); Thierry Dantoine, Cécile Laubarie-Mouret, Isabelle Saulnier, Jean-Pierre Clément, Marie-Agnès Picat, Laurence Bernard-Bourzeix, Stéphanie Willebois, Iléana Désormais, Noëlle Cardinaud (Limoges); Marc Bonnefoy, PierreLivet,Pascale Rebaudet,ClaireGédéon, Catherine Burdet, Flavien Terracol (Lyon), Alain Pesce, Stéphanie Roth, Sylvie Chaillou, Sandrine Louchart (Monaco); Kristelle Sudres, Nicolas Lebrun, Nadège Barro-Belaygues (Montauban); Jacques Touchon, Karim Bennys, Audrey Gabelle, Aurélia Romano, Lynda Touati, Cécilia Marelli, Cécile Pays (Montpellier); Philippe Robert, Franck Le Duff, Claire Gervais, Sébastien Gonfrier (Nice); Yannick Gasnier and Serge Bordes, Danièle Begorre, Christian Carpuat, Khaled Khales, Jean-François Lefebvre, Samira Misbah El Idrissi, Pierre Skolil, Jean-Pierre Salles (Tarbes).

\section{MRI Group}

Carole Dufouil (Bordeaux), Stéphane Lehéricy, Marie Chupin, Jean-François Mangin, Ali Bouhayia (Paris); Michèle Allard 
(Bordeaux); Frédéric Ricolfi (Dijon); Dominique Dubois (Foix); Marie Paule Bonceour Martel (Limoges); François Cotton (Lyon); Alain Bonafé (Montpellier); Stéphane Chanalet (Nice); Françoise Hugon (Tarbes); Fabrice Bonneville, Christophe Cognard, François Chollet (Toulouse).

\section{PET-Scans Group}

Pierre Payoux, Thierry Voisin, Julien Delrieu, Sophie Peiffer, Anne Hitzel, (Toulouse); Michèle Allard (Bordeaux); Michel Zanca (Montpellier); Jacques Monteil (Limoges); Jacques Darcourt (Nice).

\section{Medico-Economics Group}

Laurent Molinier, Hélène Derumeaux, Nadège Costa (Toulouse).

\section{Biological Sample Collection}

Christian Vincent, Bertrand Perret, Claire Vinel (Toulouse).

\section{Safety Management}

Pascale Olivier-Abbal.

\section{DSA Group}

Sandrine Andrieu, Christelle Cantet, Nicola Coley.

\section{ETHICS STATEMENT}

This study was carried out in accordance with the recommendations of the Toulouse ethics commitee (CPP SOOM II) with

\section{REFERENCES}

1. Moreh E, Jacobs JM, Stessman J. Fatigue, function, and mortality in older adults. J Gerontol A Biol Sci Med Sci (2010) 65(8):887-95. doi:10.1093/gerona/ glq064

2. Zengarini E, Ruggiero C, Mecocci P, Vellas B, Cesari M. Fatigue as a clinical sign of biological aging: exploratory analyses from the MINDED project. Geriatr Gerontol Int (2016) 16(4):533-4. doi:10.1111/ggi.12555

3. Fried LP, Tangen CM, Walston J, Newman AB, Hirsch C, Gottdiener J, et al. Frailty in older adults: evidence for a phenotype. J Gerontol A Biol Sci Med Sci (2001) 56(3):M146-56. doi:10.1093/gerona/56.3.M146

4. Fougère B, Delrieu J, Del Campo N, Soriano G, Sourdet S, Vellas B. Cognitive frailty: mechanisms, tools to measure, prevention and controversy. Clin Geriatr Med (2017) 33(3):339-55. doi:10.1016/j.cger.2017.03.001

5. Kelaiditi E, Cesari M, Canevelli M, van Kan GA, Ousset P-J, GilletteGuyonnet S, et al. Cognitive frailty: rational and definition from an (I.A.N.A./I.A.G.G.) international consensus group. J Nutr Health Aging (2013) 17(9):726-34. doi:10.1007/s12603-013-0367-2

6. Kumfor F, Halliday GM, Piguet O. Clinical aspects of Alzheimer's disease. Adv Neurobiol (2017) 15:31-53. doi:10.1007/978-3-319-57193-5_2

7. Carvalho DZ, St Louis EK, Boeve BF, Mielke MM, Przybelski SA, Knopman DS, et al. Excessive daytime sleepiness and fatigue may indicate accelerated brain aging in cognitively normal late middle-aged and older adults. Sleep Med (2017) 32:236-43. doi:10.1016/j.sleep.2016.08.023

8. Lin F, Chen D-G, Vance DE, Ball KK, Mapstone M. Longitudinal relationships between subjective fatigue, cognitive function, and everyday functioning in old age. Int Psychogeriatr (2013) 25(2):275-85. doi:10.1017/S1041610212001718

9. Verdelho A, Hénon H, Lebert F, Pasquier F, Leys D. Depressive symptoms after stroke and relationship with dementia: a three-year follow-up study. Neurology (2004) 62(6):905-11. doi:10.1212/01.WNL.0000115107.66957.8C

10. Rubin EH, Veiel LL, Kinscherf DA, Morris JC, Storandt M. Clinically significant depressive symptoms and very mild to mild dementia of the Alzheimer type. Int J Geriatr Psychiatry (2001) 16(7):694-701. doi:10.1002/gps.408 written informed consent from all subjects. All subjects gave written informed consent in accordance with the Declaration of Helsinki.

\section{AUTHOR CONTRIBUTIONS}

$\mathrm{CH}$ was responsible for data analysis and writing the manuscript. $\mathrm{PB}$ supervised the data analysis and was involved in the critical appraisal of the manuscript. NC was involved in data analysis and critical appraisal of the manuscript. PP and AS performed the $\left[{ }^{18} \mathrm{~F}\right]$ florbetapir PET. SA, MC, and BV were involved in study design and critical appraisal of the manuscript.

\section{FUNDING}

The MAPT study was supported by grants from the Gérontopôle of Toulouse, the French Ministry of Health (PHRC 2008, 2009), Pierre Fabre Research Institute (manufacturer of the omega 3 supplement), Exhonit Therapeutics SA, Avid Radiopharmaceuticals Inc. and in part by a grant from the French National Agency for Research called "Investissements d'Avenir" no. ANR-11-LABX-0018-01. The promotion of this study was supported by the University Hospital Center of Toulouse. The data sharing activity was supported by the Association Monegasque pour la Recherche sur la maladie d'Alzheimer (AMPA) and the UMR 1027 Unit INSERMUniversity of Toulouse III. Sponsor's role: None.
11. Bennett S, Thomas AJ. Depression and dementia: cause, consequence or coincidence? Maturitas (2014) 79(2):184-90. doi:10.1016/j.maturitas.2014.05.009

12. Hardy J, Allsop D. Amyloid deposition as the central event in the aetiology of Alzheimer's disease. Trends Pharmacol Sci (1991) 12(10):383-8. doi:10.1016/0165-6147(91)90609-V

13. Hardy JA, Higgins GA. Alzheimer's disease: the amyloid cascade hypothesis. Science (1992) 256(5054):184-5. doi:10.1126/science.1566067

14. Zengarini E, Ruggiero C, Pérez-Zepeda MU, Hoogendijk EO, Vellas B, Mecocci P, et al. Fatigue: relevance and implications in the aging population. Exp Gerontol (2015) 70:78-83. doi:10.1016/j.exger.2015.07.011

15. Fukuda S, Nojima J, Motoki Y, Yamaguti K, Nakatomi Y, Okawa N, et al. A potential biomarker for fatigue: oxidative stress and anti-oxidative activity. Biol Psychol (2016) 118:88-93. doi:10.1016/j.biopsycho.2016.05.005

16. Leng S, Chaves P, Koenig K, Walston J. Serum interleukin-6 and hemoglobin as physiological correlates in the geriatric syndrome of frailty: a pilot study. J Am Geriatr Soc (2002) 50(7):1268-71. doi:10.1046/j.1532-5415.2002.50315.x

17. Walston J, McBurnie MA, Newman A, Tracy RP, Kop WJ, Hirsch CH, et al. Frailty and activation of the inflammation and coagulation systems with and without clinical comorbidities: results from the Cardiovascular Health Study. Arch Intern Med (2002) 162(20):2333-41. doi:10.1001/archinte.162. 20.2333

18. Langmann GA, Perera S, Ferchak MA, Nace DA, Resnick NM, Greenspan SL. Inflammatory markers and frailty in long-term care residents. J Am Geriatr Soc (2017) 65(8):1777-83. doi:10.1111/jgs.14876

19. Tönnies E, Trushina E. Oxidative stress, synaptic dysfunction, and Alzheimer's disease. J Alzheimers Dis (2017) 57(4):1105-21. doi:10.3233/JAD-161088

20. Lee JW, Lee YK, Yuk DY, Choi DY, Ban SB, Oh KW, et al. Neuro-inflammation induced by lipopolysaccharide causes cognitive impairment through enhancement of beta-amyloid generation. J Neuroinflammation (2008) 5:37. doi:10.1186/1742-2094-5-37

21. Patterson AJ, Brown WJ, Powers JR, Roberts DC. Iron deficiency, general health and fatigue: results from the Australian Longitudinal Study on Women's Health. Qual Life Res (2000) 9(5):491-7. doi:10.1023/A:1008978114650 
22. Aapro MS, Cella D, Zagari M. Age, anemia, and fatigue. Semin Oncol (2002) 29(3 Suppl 8):55-9. doi:10.1053/sonc.2002.33534

23. Kim SA, Koo BB, Kim DE, Hwangbo Y, Yang KI. Factors affecting fatigue severity in patients with obstructive sleep apnea. Clin Respir J (2017). doi:10.1111/crj.12682

24. Leng Y,McEvoy CT, Allen IE, Yaffe K. Association of sleep-disordered breathing with cognitive function and risk of cognitive impairment: a systematic review meta-analysis. JAMA Neurol (2017). doi:10.1001/jamaneurol.2017.2180

25. Zlott DA, Byrne M. Mechanisms by which pharmacologic agents may contribute to fatigue. PM R (2010) 2(5):451-5. doi:10.1016/j.pmrj.2010.04.018

26. Yun C-H, Lee H-Y, Lee SK, Kim H, Seo HS, Bang SA, et al. Amyloid burden in obstructive sleep apnea. J Alzheimers Dis (2017) 59(1):21-9. doi:10.3233/ JAD-161047

27. Carlson ES, Magid R, Petryk A, Georgieff MK. Iron deficiency alters expression of genes implicated in Alzheimer disease pathogenesis. Brain Res (2008) 1237:75-83. doi:10.1016/j.brainres.2008.07.109

28. Silay K, Yalcin A, Akinci S, Gursoy FG, Sener Dede D. Charlson comorbidity index, inappropriate medication use and cognitive impairment: Bermuda Triangle. Wien Klin Wochenschr (2017). doi:10.1007/s00508-017-1253-4

29. Vellas B, Carrie I, Gillette-Guyonnet S, Touchon J, Dantoine T, Dartigues JF, et al. MAPT study: a multidomain approach for preventing Alzheimer's disease: design and baseline data. J Prev Alzheimers Dis (2014) 1(1):13-22.

30. Andrieu S, Guyonnet S, Coley N, Cantet C, Bonnefoy M, Bordes S, et al. Effect of long-term omega 3 polyunsaturated fatty acid supplementation with or without multidomain intervention on cognitive function in elderly adults with memory complaints (MAPT): a randomised, placebo-controlled trial. Lancet Neurol (2017) 16(5):377-89. doi:10.1016/S1474-4422(17)30040-6

31. Del Campo N, Payoux P, Djilali A, Delrieu J, Hoogendijk EO, Rolland Y, et al. Relationship of regional brain $\beta$-amyloid to gait speed. Neurology (2016) 86(1):36-43. doi:10.1212/WNL.0000000000002235

32. Joshi AD, Pontecorvo MJ, Clark CM, Carpenter AP, Jennings DL, Sadowsky $\mathrm{CH}$, et al. Performance characteristics of amyloid PET with florbetapir F 18 in patients with Alzheimer's disease and cognitively normal subjects. J Nucl Med (2012) 53(3):378-84. doi:10.2967/jnumed.111.090340

33. Alzheimer's Association. 2016 Alzheimer's disease facts and figures. Alzheimers Dement (2016) 12(4):459-509. doi:10.1016/j.jalz.2016.03.001

34. Morris JC, Storandt M, Miller JP, McKeel DW, Price JL, Rubin EH, et al. Mild cognitive impairment represents early-stage Alzheimer disease. Arch Neurol (2001) 58(3):397-405. doi:10.1001/archneur.58.3.397
35. Fleisher AS, Chen K, Liu X, Roontiva A, Thiyyagura P, Ayutyanont N, et al. Using positron emission tomography and florbetapir F18 to image cortical amyloid in patients with mild cognitive impairment or dementia due to Alzheimer disease. Arch Neurol (2011) 68(11):1404-11. doi:10.1001/ archneurol.2011.150

36. Chen J-R, Wang T-J, Huang H-Y, Chen L-J, Huang Y-S, Wang Y-J, et al. Fatigue reversibly reduced cortical and hippocampal dendritic spines concurrent with compromise of motor endurance and spatial memory. Neuroscience (2009) 161(4):1104-13. doi:10.1016/j.neuroscience.2009.04.022

37. McDermott CM, LaHoste GJ, Chen C, Musto A, Bazan NG, Magee JC. Sleep deprivation causes behavioral, synaptic, and membrane excitability alterations in hippocampal neurons. J Neurosci (2003) 23(29):9687-95.

38. Kang J-E, Lim MM, Bateman RJ, Lee JJ, Smyth LP, Cirrito JR, et al. Amyloidbeta dynamics are regulated by orexin and the sleep-wake cycle. Science (2009) 326(5955):1005-7. doi:10.1126/science.1180962

39. Sprecher KE, Bendlin BB, Racine AM, Okonkwo OC, Christian BT, Koscik RL, et al. Amyloid burden is associated with self-reported sleep in nondemented late middle-aged adults. Neurobiol Aging (2015) 36(9):2568-76. doi:10.1016/j. neurobiolaging.2015.05.004

40. Brown BM, Rainey-Smith SR, Villemagne VL, Weinborn M, Bucks RS, Sohrabi HR, et al. The Relationship between Sleep Quality and Brain Amyloid Burden. Sleep (2016) 39(5):1063-8. doi:10.5665/sleep.5756

41. Vestergaard S, Nayfield SG, Patel KV, Eldadah B, Cesari M, Ferrucci L, et al. Fatigue in a representative population of older persons and its association with functional impairment, functional limitation, and disability. J Gerontol A Biol Sci Med Sci (2009) 64(1):76-82. doi:10.1093/gerona/gln017

Conflict of Interest Statement: The authors declare that the research was conducted in the absence of any commercial or financial relationships that could be construed as a potential conflict of interest.

Copyright (C) 2017 Hooper, De Souto Barreto, Coley, Cesari, Payoux, Salabert, Andrieu and Vellas. This is an open-access article distributed under the terms of the Creative Commons Attribution License (CC BY). The use, distribution or reproduction in other forums is permitted, provided the original author(s) or licensor are credited and that the original publication in this journal is cited, in accordance with accepted academic practice. No use, distribution or reproduction is permitted which does not comply with these terms. 